\title{
Swinging arms in multifunctional enzymes and the specificity of post-translational modification
}

\author{
R. N. Perham and P. A. Reche
}

Cambridge Centre for Molecular Recognition. Department of Biochemistry, University of Cambridge, 80 Tennis Court Road. Cambridge CB2 IGA, U.K.

\section{Introduction}

Covalently attached prosthetic groups serve as swinging arms in several different and wellcharacterized multifunctional enzymes. Notable among these are the lipoyl-lysine residues in 2-oxo acid dehydrogenase multienzyme complexes $[1-3]$ and the glycine cleavage system [4-6], the biotinyl-lysine residues in various ATP-dependent carboxylases $[7,8]$ and the phosphopantetheinyl-serine residues in fatty acid [97 and polyketide [10] synthases. In all these instances, the swinging arm is used to ferry substrate between the active sites that function successively in a multistep catalytic reaction. Several explanations have been proposed for the advantages supposedly conferred on a multifunctional protein by virtue of these swinging arms $[11,12]$ : an enhancement of catalytic efficiency, the potential for substrate channelling, and an opportunity to protect an otherwise unstable catalytic intermediate (the 'hot potato hypothesis').

Another important feature is the mechanism by which the target side chain in the parent protein is selected for post-translational modification. In each case it has become apparent that there is an enzyme, a ligase or transferase, that catalyses the formation of an anide bond with the amino group of a lysine residue (lipoylation or biotinylation) or phosphodiester bond with the hydroxyl group of a serine residue (pantetheinylation) as a means of attaching the prosthetic group $([13-16]$ and references therein). However, only recently has it become clear, at least in the case of lipoylation [17] and bintinylation [18], how these ligases reconnize their target protein and identify the particular side chain for modification.

We review here our current knowledge of the lipoyl-lysine and biotinyl-lysine swinging arms in multienzyme complexes. Parallels between lipoic acid and biotin have long been drawn and it has now become apparent that there is an underlying structural similarity in the proteins that become lipoylated or biotinylated.

Abbreviations used: I.PI, lipoyl protein ligase; BPL, biotinyl protein ligase.
Moreover, the similarity extends to the molecular basis of the post-translational modifications. There are no obvious structural features in common with the enzymes that utilize pantetheinic acid as a swinging arm, but it is likely that similar considerations will apply.

\section{The lipoyl domain and the biotinyl domain}

In lipoylated and biotinylated proteins, the prosthetic group is covalently attached to the $\mathrm{N}^{*}$-amino group of a lysine residue in an independently folded domain of about 80 amino acid residues. In 2-oxo acid dehydrogenase complexes, the lipoyl domain is found at the $\mathrm{N}$-terminus of the dihydrolipoyl acyltransferase (E2) component, as a single entity or repeated up to three times in tandem array, depending on the origin of the complex [2,3]. Its structure has been determined by NMR spectroscopy [19-23] and takes the form of a flatened $\beta$-barrel composed of two four-stranded $\beta$-sheets. The $N$ - and $\mathrm{C}$-terminal residues lie close together in space in one sheet and the lipoyl-lysine residue is located in an exposed $\beta$-turn in the other sheet (Figure 1). A similar structure has been determined for the H-protein of the glycine cleavage system, except that the 80 amino acid residue lipoyl domain has $\mathrm{N}$ - and C-terminal extensions of approximately 20 residues each $[24]$.

The biotinyl domain in biotin-dependent carboxylases shows only vestigial amino acid sequence similarity to the lipoyl domain but, as predicted [25], has an homologous three-dimensional structure (Figure 1). As determined by X-ray crystallography [26] and NMR spectroscopy ([27] E. L. Roberts, N.-C. Shu, M. J. Howard, R. W. Broadhurst, A. Chapman-Smith, J. C. Wallace, T. W. Morris, J. E. Cronan and R. N. Perham, unpublished work), it too is a flattened $\beta$-barrel, comprising two four-stranded $\beta$-sheets, with the $\mathrm{N}$ - and C-terminal residues close together in space in one sheet and the biotinyllysine residue located in a highly conserved Met1 ys-Met sequence in an exposed $\beta$-turn in the other sheet. In both instances, therefore, the modified lysine residue is well placed to act as a 
swinging arm in the catalytic mechanism of the parent multienzyme system.

\section{Importance of the lipoyl and biotinyl domains}

On the face of it, there is nothing in the chemical mechanism of the oxidative decarboxylation of 2-oxo acids [28] that would require the lipoyl group to be attached to a protein domain in the E2 component. However, cleavage of the lipoyl domain from the remainder of the $\mathrm{E} 2$ chain by limited proteolysis, while leaving the residual multienzyme complex and the $\mathrm{E} 1$ (a thiamin diphosphate-dependent decarboxylase) and E3 (dihydrolipoyl dehydrogenase) components intact and fully active, causes the overall catalytic

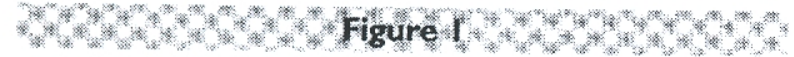

Structures of the biotinyl domain of $E$. coli acetyl-CoA carboxylase and the lipoyl domain of B. stearothermophilus pyruvate dehydrogenase complex

The wo / sheet are indlated in ligh and dak shades. The figure was prepared using the program: MOULCRIPT [27a].

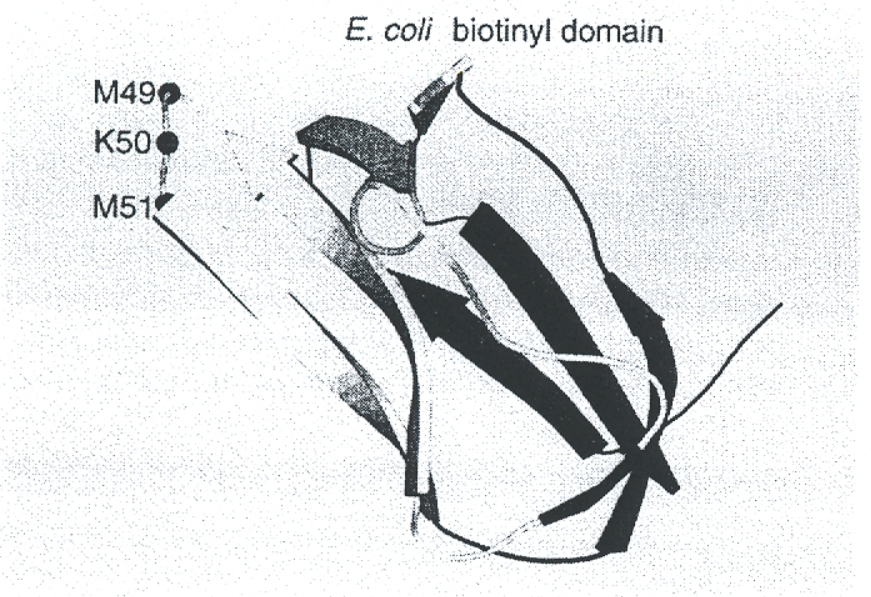

B. stearothermophilus E2p lipoyl domain

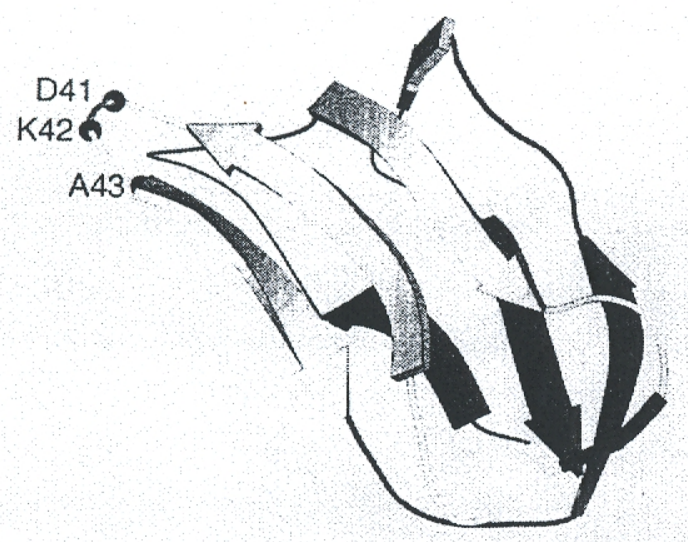

activity of the pyruvate dehydrogenase complex of Escherichia coli to fall virtually to undetectable levels $[29,30]$. Similar results are obtained when the overall complex is reconstituted from the truncated $\mathrm{C} 2$ chain and free lipoyl domain [31]. This presumably illustrates the rate enhancement that is achieved by covalent attachment of the lipoyl domain to the complex, with the consequent increase in its local concentration.

More subtly, perhaps, attachment of the lipoyl group to the lipoyl domain is required for the reductive acylation of the dithiolane ring by the E1 component of 2-oxo acid dehydrogenase complexes. Thus free lipoic acid is not a substrate for E1, although it is for E2 and E3 [32]. However, the lipoyl group attached to a lipoyl domain becomes a highly effective substrate, as evidenced by the value of $k_{\mathrm{cat}} / K_{\mathrm{th}}$ being raised by a factor of $10^{4}$ for the lipoyl domain of the $E$ coli pyruvate dehydrogenase complex [33]. Moreover. the lipoyl domain confers on its pendant lipoyl group specificity for reductive acylation only by the E1 component of its parent 2-oxo acid dehydrogenase complex [33]. E1 catalyses the first committed step in the oxidative decarboxylation of 2-oxo acids and, given that the lipoyl group is common to a number of enzymes, the specificity of the protein-protein interaction between $\mathrm{E} 1$ and its cognate lipoyl domain thereby provides an elegant molecular basis for substrate channelling in these complexes [2].

For it to serve as a substrate, attachment of the biotin to its domain is likewise essential for all but two biotin-dependent carboxylases: acetylCoA carboxylase and $\beta$-methylcrotonyl-CoA carboxylase [34]. Again, it is likely that the biotinyl domain is not merely an anchor for the swinging arm but participates actively in the multienzyme system in which it is found.

\section{Interactions of the lipoyl domain}

Detailed studies have been made of the interactions of the lipoyl domain with the E1 component of the prruvate dehydrogenase complex of Bacilhus stearothermophilus. In particular, it has been found that replacement of the amino acid residues flanking the lipoyl-lysine residue in the $\beta$-turn (Figure 1) can have a major deleterious effect on the reductive acetylation by $\mathrm{E} 1$ in the presence of pyruvate [17]. Likewise, deletion of part of the prominent surface loop between the first and second $\beta$-strands which lies close in space to the lipoyl-lysine $\beta$-turn (Figure 1) virtually abolishes reductive acetylation, and this 
cannot be restored by reconstituting the loop with amino acid sequences taken from other lipoyl domains [35].

The idea that the E1 component recognizes its cognate lipoyl domain, at least in part, by interactions with residues in this surface loop and the $\beta$-turn is reinforced by NMR data [35] On the basis of chemical shift changes noted in the heteronuclear multiple quantum coherence (HMQC) spectrum of the apo form of the $B$. stearothermophilus lipoyl domain in the presence of its E1 component, it appears that significant and specific contact is made between the two proteins over this region, as indicated in Figure 2. The lipoylated form binds too tightly to $\mathrm{E} 1$ for comparable experiments to be possible [35] but insufficiently tightly [36] for it to be possible to co-crystallize a complex. The recognition of the lipoyl domain by E1 by transient contact and the presentation of the pendant lipoyl group for reductive acylation is doubtless more complicated than these experiments have thus far been able to reveal: further analysis may have to await the determination of a three-dimensional structure of the $\mathrm{E} 1$ component to complement that of the lipoyl domain.

\section{The specificity of post-translational modification}

The ligases that catalyse the post-translational modification of the lipoyl and biotinyl domains have much in common. The mechanism of lipoylation is a two-step process: activation of the carboxyl group of lipoic acid by reaction with ATP

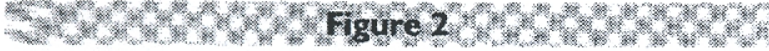

Location in the B. stearothermophilus lipoyl domain of residues exhibiting changes in the chemical shift of cross-peaks in the HMQC NMR spectrum of the domain in the presence of the partner EI

The wo $\beta$-sheets are indicated in light and dark shades, as in Figure 1. (Data from [35])

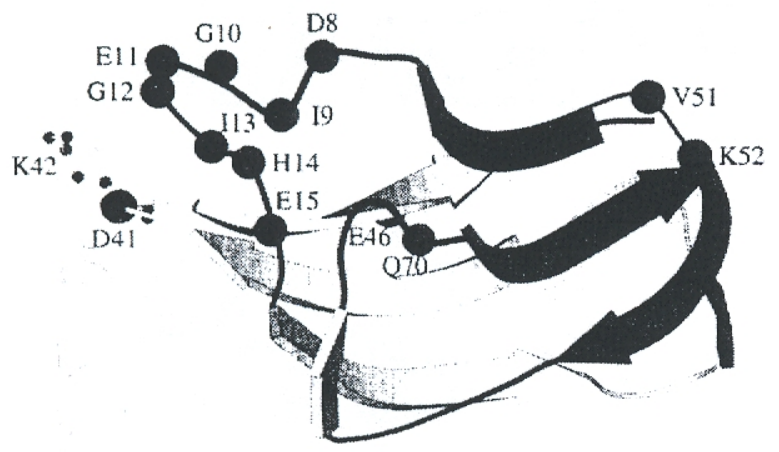

to form lipoyl-5'-AMP and elimination of pyrophosphate, followed by transfer of the lipoyl group to the target lysine residue of the lipoyl domain and release of AMP. In $E$. coli two genes ( $I p l A$ and $l p B B$ ) have been postulated to encode independent pathways for the attachment of the lipoyl group to the apo-protein [14]. The IplA gene has been cloned and over-expressed [37]; the product, lipoyl protein ligase (LPL), utilizes D-lipoic acid as its preferred substrate but can use octanoic acid and r-lipoic acid [38], corresponding to the $B$ form of the enzyme described previously [39]. The $R$-enantiomer of lipoic acid is required by the $\mathrm{E} 1$ component in the pyruvate and 2-oxoglutarate dehydrogenase complexes [40]. In contrast, the product of the lipB gene relies on an endogenous source of lipoic acid supplied by the liph-dependent biosynthetic route [14] and is likely to be responsible for most of the aberrant octanoylation of lipoyl domains that occurs under conditions of lipoic acid deficiency $[41,42]$. The bovine lipov] protein ligase, for which a cDNA has been cloned and expressed in $E$ coli [43], shows about $35 \%$ sequence identity with the E. coli LPL. Curiously, however, it cannot catalyse the initial activation of the lipoic acid to form lipoyl-AMP, for which another enzyme appears to be required [15]. A detailed comparison of the bovine and $E$. coli enzymes may thus help to delineate the two active sites.

In E. coli biotinyl protein ligase, BPL, is encoded by the bird gene [13] and its X-ray crystal structure has been solved [44]. The reaction mechanism resembles that of LPL: formation of biotinyl-5'-AMP from biotin and ATP, followed by transfer of the biotinyl group to the target lysine residue of the biotinyl domain and release of AMP. Interestingly, BPL also acts as as a repressor to regulate the biosynthesis of biotin by the biotin operon, with biotin-5'-AMP as the co-repressor [45].

Perhaps the most notable observation to emerge from recent work on LPL and BPL is the molecular basis of their selection of the correct target residue $[17,18]$. Despite the structural similarity between the lipoyl and biotinyl domains, the ligases are highly specific for their respective partners. In the lipoyl domain the lysine residue is found in a moderately conserved Asp-Lys-Ala sequence, and in the biotinyl domain the lysine residue resides in a strongly conserved Met-Lys-Met sequence. Site-directed mutagenesis cxperiments on the biotinyl domain, 
in which the Met-Lys-Met motif was systematically varied, have demonstrated that BPL is relatively insensitive to changes in the amino acid sequence flanking the lysine residue but is unable to function if the lysine residue is shifted one residue to the $\mathrm{N}$ - or $\mathrm{C}$-terminal side of its normal position in the exposed $\beta$-turn in the apo-domain (Figure 3). Importation of the AspLys-Ala motif into the biotinyl domain renders it incapable of biotinylation in vizo but the domain then becomes a poor substrate for lipoylation and aberrant octanoylation [18].

Similar results have been obtained with the post-translational modification of the lipoyl domain. Again, the target lysine residue must be correctly positioned in the $\beta$-turn if it is to become lipoylated and the flanking sequence turns out to be relatively unimportant. Likewise, replacing the Asp-Lys-Ala motif with the MetLys-Met sequence widely conserved in biotinyl domains is insufficient to designate the domain for biotinylation [17]. Thus, unlike many enzymes responsible for post-translational modification, e.g. phosphokinases, LPL and BPL. require a folded domain to act on; and the target lysine residue must be presented in the exposed

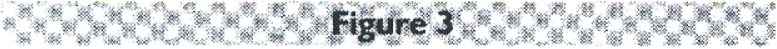

Post-translational modification of the wild-type and mutant biotinyl domains in vivo

Subgenes encoding the protein donains were expressed in $E$. con cells transformed with the relevant plasmids. The purified domains were subjected to non denaturing PAGE. (a) $E$ coli cells grown in the presence of $10 \mathrm{mg} / \mathrm{ml}$ of $\mathrm{mbiotin:}$ lane 1, wild type domain (Met-Lys-Met): lane 2, mutant Met-Ala Lys; lane 3. mutant Lys-Ala.Met: lane 4. mutant Asp Lys-Ala; lane 5, mutant Lys-Lys-Met: lane 6. mutant Met Lys-Lys. (b) Asp-Lys-Ala mutant doman purifed from $E$. coll cells grown in the presence of: tane 1. $10 \mathrm{mg} / \mathrm{l}$ biotin: lane $2.10 \mathrm{mg} / \mathrm{l}$ - lipoic acid lane 3.10 $\mathrm{mg} / \mathrm{pctanoc}$ acid (Oata from [ 18$]$ )

a

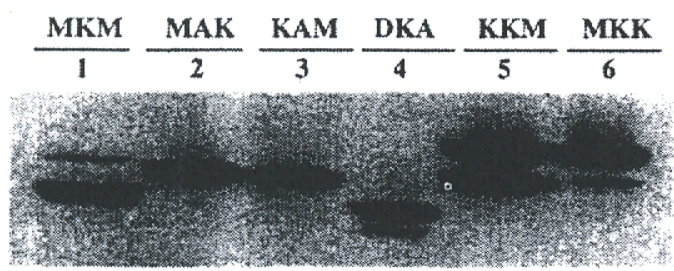

b

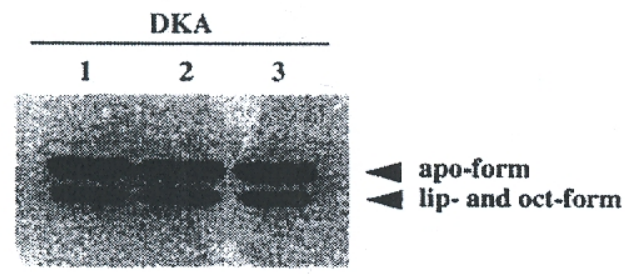

$\beta$-turn in the particular domain in which it normally resides.

\section{Envoi}

The structural analysis of the lipoyl and biotinyl domains has uncovered some further intriguing features that are clearly important to the enzymic function of their parent multienzyme complexes. Although attaching the lipoyl group to a lipoyl domain has a profound effect on the value of $k_{\mathrm{cat}} /$ $K_{\mathrm{m}}$ for the reductive acylation of the pendant dithiolane ring (see above), the lipoyl-lysine residue is effectively free to rotate on the surface of the protein, as befits a classical swinging arm [2]. In contrast, the biotinyl-lysine residue on the surface of the biotinyl domain of the acetyl-CoA carboxylase of $E:$ col is clearly localized by interaction with the protein in the structure deduced from X-ray crystallography [26] and solution NMR spectroscopy (E. L. Roberts, N.-C. Shu, M. J. Howard, R. W. Broadhurst, A. ChapmanSmith, J. C. Wallace, T. W. Morris, J. E. Cronan and R. N. Perham, unpublished work), though there is no evidence of similar biotin-protein interactions in the $1.3 \mathrm{~S}$ subunit of Propionibacterium shermanii transcarboxylase [46]. It is not immediately obvious what purpose, if any, is served by the prior localization of the biotinyllysine residue in a holo-domain. The lipoyllysine residue in the H-protein of the glycine cleavage system of pea is also localized [24], but switches to a new position when charged with substrate, such that the aminomethylated derivative, which would otherwise be unstable, is sequestered in a surface cavity of the domain unique to the H-protein [47]. In this instance, the swinging arm is fulfilling the expectation of the 'hot potato hypothesis' [12].

Swinging arms occupy a special place in the study of multi-step catalysis by multienzyme systems. The recent spate of new knowledge about the structure of the proteins that harbour them, and the enzymes that attach them, has put them in a new light while leaving plenty of interesting dark corners still to be explored.

We thank the Federation of European Biochemical Societies for a Fellowship awarded to P.R and the BBSRC for a research grant awarded to R.N.P. The core facilitics of the Cambridge Centre for Molecular Recognition are supported by the BBSRC and The Wellowe Trust.

1 Reed, 1. J. and Hackert, M. L. (1990) J. Biol. Chem. 265, 8971-8974 
2 Perham, R. N. (1991) Biochemistry 30, 8501-8512

3 Berg, A. and de Kok, A. (1997) Biol. Chem. 378, 617-634

4 Fujiwara, K., Okamura-Ikeda, K. and Motokawa, Y. (1992) J. Biol. Chem. 267, 20011-20016

5 Okamura-Ikeda, K., Ohmura, Y., Fujiwara, K. and Motokawa, Y. (1993) Eur. J. Biochem. 216, 539-548

6 Macherel, D., Bourguignon, J., Forest, E., Faure, M., Cohen-Addad, C. and Douce, R. (1996) Eur. J. Biochem. 236, 27-33

7 Salmons, D., Thornton, C. G., Murtif, V. L., Kumar, G. K., Haase, F. C. and Wood, H. G. (1988) J. Biol. Chem. 263, 6461-6464

8 Knowles, J, R. (1989) Annu. Rev. Biochem. 58, 195-221

9 Holak, T. A., Nilges, M., Prestegard, J. H., Gronenborn, A. and Clore, G. M. (1988) Eur. J. Biochem. 175, 9-15

10 Crump, M. P., Crosby, J., Dempsey, C. F., Parkinson, J. A., Murray, M., Hopwood, D. A. and Simpson, T. J. (1997) Biochemistry 36, 6000-6008

11 Reed, L. J. (1974) Acc. Chem. Res. 7, 40-46

12 Perham, R. N. (1975) Phil. Trans. R. Soc. London Ser. B 272, 123-136

13 Howard, P. K., Shaw, J. and Otsuka, A. J. (1985) Gene 35, 321-331

14 Morris, T. W., Reed, K. E. and Cronan, Jr., J. E. (1995) J. Bacteriol. 177, 1-10

15 Fujiwara, K., Okamura-Ikeda, K. and Motokawa, Y. (1997) J. Biol. Chem. 272, 31974-31978

16 Walsh, C. T., Gehring, A. M., Weinreb, P. H., Quadri, L. E. N. and Flugel, R. S. (1997) Curr. Opin. Chem. Biol. 1, 304-315

17 Wallis, N. G. and Perham, R. N. (1994) J. Mol. Biol. 236, 209-216

18 Reche, P., Li, Y.-L., Fuller, C., Eichhorn, K. and Perham, R. N. (1998) Biochem. J. 329, 589-596

19 Dardel, F., Davis, A. L., Laue, E. D. and Perham, R. N. (1993) J. Mol. Biol. 229, 1037-1048

20 Green, J. D. F., Laue, E. D., Perham, R. N., Ali, S. T. and Guest, J. R. (1995) J. Mol. Biol. 248, 328-343

21 Ricaud, P. M., Howard, M. J., Roberts, E. L., Broadhurst, R. W. and Perham, R. N. (1996) J. Mol. Biol. 264, 179-190

22 Berg, A., Vervoort, J. and de Kok, A. (1996) J. Mol. Biol. 261, 432-442

23 Berg, A., Vervoort, J. and de Kok, A. (1997) Eur. J. Biochem. 244, 352-360

24 Pares, S., Cohen-Addad, C., Sieker, L., Neuburger, M. and Douce, R. (1994) Proc. Natl. Acad. Sci. U.S.A. 91, 4850-4853

25 Brocklehurst, S. M. and Perham, R. N. (1993) Prot. Sci. 2, 626-639
26 Athappilly, F. K. and Hendrickson, W. A. (1995) Structure 3, 1407-1419

27 Yao, X., Wei, D., Sodern, C., Summers, M. F. and Beckett, D. (1997) Biochemistry 36, 15089-15100

27a Kraulis, P. J. (1991) J. Appl. Crystallog. 24, 946-950

28 Gruys, K. J., Datta, A. and Frey, P. A. (1989) Biochemistry 28, 9071-9080

29 Hale, G. and Perham, R. N. (1979) Eur. J. Biochem. 94, 119-126

30 Bleile, D. M., Munk, P., Oliver, R. M. and Reed, L. J. (1979) Proc. Natl. Acad. Sci. U.S.A. 76, 4385-4389

31 Russell, G. C., Williamson, A. and Guest, J. R. (1989) FEMS Microbiol. Lett. 60, 267-272

32 Reed, L. J., Koike, M., Levitch, M. E. and Leach, F. R. (1958) J. Biol. Chem. 232, 143-158

33 Graham, L. D., Packman, L. C. and Perham, R. N. (1989) Biochemistry 28, 1574-1581

34 Waldrop, G. L., Rayment, I. and Holden, H. M. (1994) Biochemistry 33, 10249-10256

35 Wallis, N. G., Allen, M. D., Broadhurst, R. W., Lessard, I. A. D. and Perham, R. N. (1996) J. Mol. Biol. 263, 436-474

36 Graham, L. D. and Perham, R. N. (1990) FEBS Lett. 262, 241-244

37 Morris, T. W., Reed, K. E. and Cronan, Jr., J. E. (1994) J. Biol. Chem. 269, 16091-16100

38 Green, D. E., Morris, T. W., Green, J., Cronan, Jr., J. E. and Guest, J. R. (1995) Biochem. J. 309, 853-862

39 Brookfield, D. E., Green, J., Ali, S. T., Machado, R. S. and Guest, J. R. (1991) FEBS Lett. 295, 13-16

40 Yang, Y.-S. and Frey, P. A. (1989) Arch. Biochem. Biophys. 268, 465-474

41 Ali, S. T., Moir, A. J. G., Ashton, P. R., Engel, P. C. and Guest, J. R. (1990) Mol. Microbiol. 4, 943-950

42 Dardel, F., Packman, L. C. and Perham, R. N. (1990) FEBS Lett. 264, 206-210

43 Fujiwara, K., Okamura-Ikeda, K. and Motokawa, Y. (1996) J. Biol. Chem. 271, 12932-12936

44 Wilson, K. P., Shewchuk, L. M., Brennan, R. G., Otsuka, A. J. and Matthews, B. W. (1992) Proc. Natl. Acad. Sci. U.S.A. 89, 9257-9261

45 Cronan, Jr., J. E. (1989) Cell 58, 427-428

46 Reddy, D. V., Shenoy, B. C., Carey, P. R. and Sönnischen, F. D. (1997) Biochemistry 36, 14676-14682

47 Cohen-Addad, C., Pares, S., Sieker, L., Neuberger, M. and Douce, R. (1995) Nature Struct. Biol. 2, $63-68$

Received 1 April 1998 
swinging arm in the catalytic mechanism of the parent multienzyme system.

\section{Importance of the lipoyl and biotinyl domains}

On the face of it, there is nothing in the chemical mechanism of the oxidative decarboxylation of 2-oxo acids [28] that would require the lipoyl group to be attached to a protein domain in the E2 component. However, cleavage of the lipoyl domain from the remainder of the $\mathrm{E} 2$ chain by limited proteolysis, while leaving the residual multienzyme complex and the El (a thiamin diphosphate-dependent decarboxylase) and E3 (dihydrolipoyl dehydrogenase) components intact and fully active, causes the overall catalytic

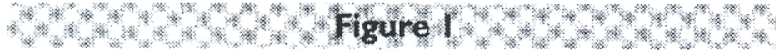

Structures of the biotinyl domain of $E$. coli acetyl-CoA carboxylase and the lipoyl domain of B. stearothermophilus pyruvate dehydrogenase complex

The two fi-sheets are indicated in light and dark shades. The figure was prepared using the program MOLSCRIPT [27a].

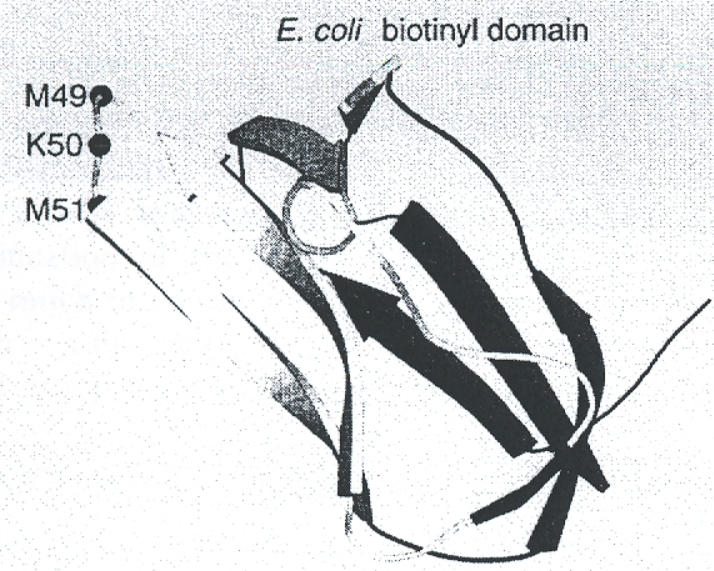

B. stearothermophilus E2p lipoyl domain

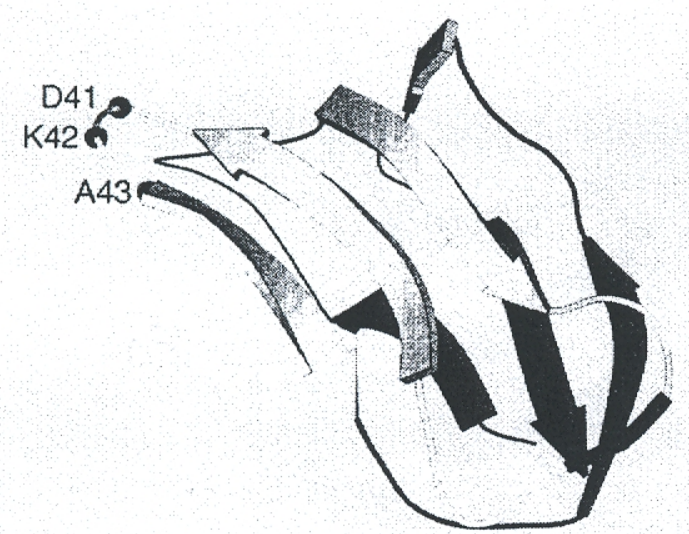

activity of the pyruvate dehydrogenase complex of Escherichia coli to fall virtually to undetectable levels $[29,30]$. Similar results are obtained when the overall complex is reconstituted from the truncated $\mathrm{C} 2$ chain and free lipoyl domain [31]. This presumably illustrates the rate enhancement that is achieved by covalent attachment of the lipoyl domain to the complex, with the consequent increase in its local concentration.

More subtly, perhaps, attachment of the lipoyl group to the lipoyl domain is required for the reductive acylation of the dithiolane ring by the E1 component of 2-oxo acid dehydrogenase complexes. Thus free lipoic acid is not a substrate for E1, although it is for E2 and E3 [32]. However, the lipoyl group attached to a lipoyl domain becomes a highly effective substrate, as evidenced by the value of $k_{\text {cat }} / K_{\text {tn }}$ being raised by a factor of $10^{4}$ for the lipoyl domain of the $E$. coli pyruvate dehydrogenase complex [33]. Moreover, the lipoyl domain confers on its pendant lipoyl group specificity for reductive acylation only by the E1 component of its parent 2-oxo acid dehydrogenase complex [33]. E1 catalyses the first committed step in the oxidative decarboxylation of 2-oxo acids and, given that the lipoyl group is common to a number of enzymes, the specificity of the protein-protein interaction between $\mathrm{E} 1$ and its cognate lipoyl domain thereby provides an elegant molecular basis for substrate channelling in these complexes [2].

For it to serve as a substrate, attachment of the biotin to its domain is likewise essential for all but two biotin-dependent carboxylases: acetylCoA carboxylase and $\beta$-methylcrotonyl-CoA carboxylase [34]. Again, it is likely that the biotinyl domain is not merely an anchor for the swinging arm but participates actively in the multienzyme system in which it is found.

\section{Interactions of the lipoyl domain}

Detailed studies have been made of the interactions of the lipoyl domain with the E1 component of the pyruvate dehydrogenase complex of Bacillus stearothermophilus. In particular, it has been found that replacement of the amino acid residues flanking the lipoyl-lysine residue in the $\beta$-turn (Figure 1) can have a major deleterious effect on the reductive acetylation by E1 in the presence of pyruvate [17]. Likewise, deletion of part of the prominent surface loop between the first and second $\beta$-strands which lies close in space to the lipoyl-lysine $\beta$-turn (Figure 1 ) virtually abolishes reductive acetylation, and this 
cannot be restored by reconstituting the loop with amino acid sequences taken from other lipoyl domains [35].

The idea that the E1 component recognizes its cognate lipoyl domain, at least in part, by interactions with residues in this surface loop and the $\beta$-turn is reinforced by NMR data [35]. On the basis of chemical shift changes noted in the heteronuclear multiple quantum coherence (HMQC) spectrum of the apo form of the $B$. stearothermophilus lipoyl domain in the presence of its E1 component, it appears that significant and specific contact is made between the two proteins over this region, as indicated in Figure 2. The lipoylated form binds too tightly to E1 for comparable experiments to be possible [35] but insufficiently tightly [36] for it to be possible to co-crystallize a complex. The recognition of the lipoyl domain by $\mathrm{E} 1$ by transient contact and the presentation of the pendant lipoyl group for reductive acylation is doubtless more complicated than these experiments have thus far been able to reveal; further analysis may have to await the determination of a three-dimensional structure of the E1 component to complement that of the lipoyl domain.

\section{The specificity of post-translational modification}

The ligases that catalyse the post-translational modification of the lipoyl and biotinyl domains have much in common. The mechanism of lipoylation is a two-step process: activation of the carboxyl group of lipoic acid by reaction with ATP

\section{$5300 \%$ Figure?}

Location in the B. stearothermophilus lipoyl domain of residues exhibiting changes in the chemical shift of cross-peaks in the HMQC NMR spectrum of the domain in the presence of the partner EI

The two $\beta$-sheets are indicated in light and dark shades, as in Figure 1. (Oata from [35])

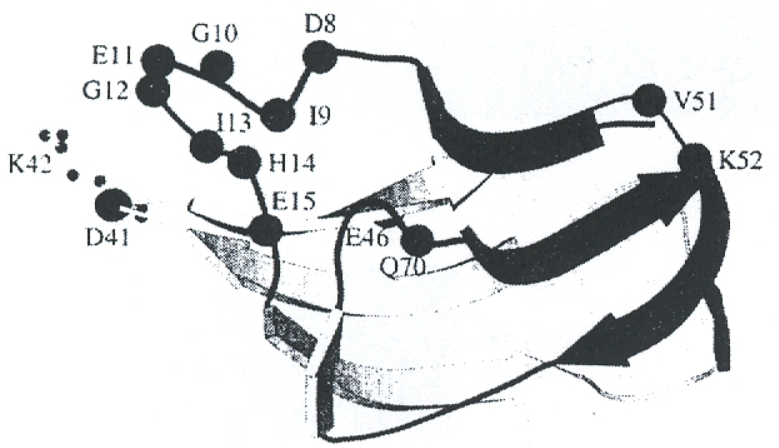

to form lipoyl-5'-AMP and elimination of pyrophosphate, followed by transfer of the lipoyl group to the target lysine residue of the lipoyl domain and release of AMP. In $E$. coli two genes ( $I D L A$ and $l i p B$ ) have been postulated to encode independent pathways for the attachment of the lipoyl group to the apo-protein [14]. The $1 p l A$ gene has been cloned and over-expressed [37]; the product, lipoyl protein ligase (LPL), utilizes D-lipoic acid as its preferred substrate but can use octanoic acid and r-lipoic acid [38], corresponding to the $\mathrm{B}$ form of the enzyme described previously [39]. The $R$-enantiomer of lipoic acid is required by the $\mathrm{E} 1$ component in the pyruvate and 2-oxoglutarate dehydrogenase complexes [40]. In contrast, the product of the lipB gene relies on an endogenous source of lipoic acid supplied by the liph 1-dependent biosynthetic route [14] and is likely to be responsible for most of the aberrant octanoylation of lipoyl domains that occurs under conditions of lipoic acid deficiency $[41,42]$. The bovine lipoyl protein ligase, for which a cDNA has been cloned and expressed in $E$. coli [43], shows about $35 \%$ sequence identity with the E. coli LPL. Curiously, however, it cannot catalyse the initial activation of the lipoic acid to form lipoyl-AMP, for which another enzyme appears to be required [15]. A detailed comparison of the bovine and $E$. coli enzymes may thus help to delineate the two active sites.

In E. coll biotinyl protein ligase, BPL, is encoded by the bird gene [13] and its X-ray crystal structure has been solved [44]. The reaction mechanism resembles that of LPL: formation of biotinyl-5'-AMP from biotin and ATP, followed by transfer of the biotinyl group to the target lysine residue of the biotinyl domain and release of AMP. Interestingly, BPL also acts as as a repressor to regulate the biosunthesis of biotin by the biotin operon, with biotin-5'-AMP as the co-repressor [45].

Perhaps the most notable observation to emerge from recent work on LPL and BPL is the molecular basis of their selection of the correct target residue $[17,18]$. Despite the structural similarity between the lipoyl and biotinyl domains, the ligases are highly specific for their respective partners. In the lipoyl domain the lysine residue is found in a moderately conserved Asp-Lys-Ala sequence, and in the biotinyl domain the lysine residue resides in a strongly conserved Met-Lys-Met sequence. Site-directed mutagenesis experiments on the biotinyl domain, 
in which the Met-Lys-Met motif was systematically varied, have demonstrated that BPL is relatively insensitive to changes in the amino acid sequence flanking the lysine residue but is unable to function if the lysine residue is shifted one residue to the $\mathrm{N}$ - or $\mathrm{C}$-terminal side of its normal position in the exposed $\beta$-turn in the apo-domain (Figure 3). Importation of the AspLys-Ala motif into the biotinyl domain renders it incapable of biotinylation in vizo but the domain then becomes a poor substrate for lipoylation and aberrant octanoylation [18].

Similar results have been obtained with the post-translational modification of the lipoyl domain. Again, the target lysine residue must be correctly positioned in the $\beta$-turn if it is to become lipoylated and the flanking sequence turns out to be relatively unimportant. Likewise, replacing the Asp-Lys-Ala motif with the MetLys-Met sequence widely conserved in biotinyl domains is insufficient to designate the domain for biotinylation [17]. Thus, unlike many enzymes responsible for post-translational modification, e.g. phosphokinases, LPL and BPL require a folded domain to act on; and the target lysine residue must be presented in the exposed

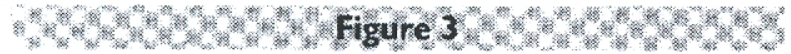

Post-translational modification of the wild-type and mutant biotinyl domains in vivo

Subgenes encodng the protein donains were expressed in $E$ coli celis transformed with the relevant plasmids. The purifed domans were subjected to non denaturing PAGE. (a) $E$ coi cells grown in the presence of $10 \mathrm{mg} / \mathrm{m}$ of 1 -botin: lane 1, wild type domain (Met-Lys.Me1): lane 2. mutant Met-Ala Lys: lane 3. mutant Lys. Ala Met: lane 4, mutant Asp -Lys Aä; tane S, mutant L.ys Lys Met: lane 6. mutant Met Lys Lys. (b) Asp Lys Ala mutant coman purifed from E. coli celis grown in the presence of: tane 1. $10 \mathrm{mg} / \mathrm{l}$ biotn lane $2.10 \mathrm{mg} / \mathrm{l}$ lipoic acd lane 3.10 mglloctanok act (Data trom [8])

a

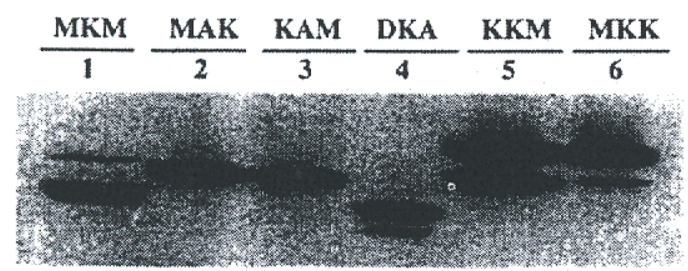

b

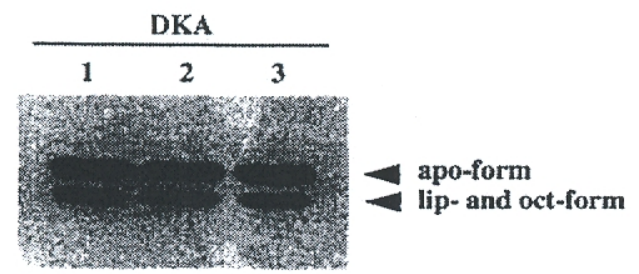

$\beta$-turn in the particular domain in which it normally resides.

\section{Envoi}

The structural analysis of the lipoyl and biotinyl domains has uncovered some further intriguing features that are clearly important to the enzymic function of their parent multienzyme complexes. Although attaching the lipoyl group to a lipoyl domain has a profound effect on the value of $k_{\text {cat }} /$ $K_{\mathrm{m}}$ for the reductive acylation of the pendant dithiolane ring (see above), the lipoyl-lysine residue is effectively free to rotate on the surface of the protein, as befits a classical swinging arm [2]. In contrast, the biotinyl-lysine residue on the surface of the biotinyl domain of the acetyl-CoA carboxylase of $E$. coli is clearly localized by interaction with the protein in the structure deduced from X-ray crystallography [26] and solution NMR spectroscopy (E. L. Roberts, N.-C. Shu, M. J. Howard, R. W. Broadhurst, A. ChapmanSmith, J. C. Wallace, T. W. Morris, J. E. Cronan and R. N. Perham, unpublished work), though there is no evidence of similar biotin-protein interactions in the $1.3 \mathrm{~S}$ subunit of Propionibacterium shermanii transcarboxylase [46]. It is not immediately obvious what purpose, if any, is served by the prior localization of the biotinyllysine residue in a holo-domain. The lipoyllysine residue in the H-protein of the glycine cleavage system of pea is also localized [24], but switches to a new position when charged with substrate, such that the aminomethylated derivative, which would otherwise be unstable, is sequestered in a surface cavity of the domain unique to the H-protein [47]. In this instance, the swinging arm is fulfilling the expectation of the 'hot potato hypothesis' [12].

Swinging arms occupy a special place in the study of multi-step catalysis by multienzyme systems. The recent spate of new knowledge about the structure of the proteins that harbour them, and the enzymes that attach them, has put them in a new light while leaving plenty of interesting dark comers still to be explored.

We thank the Federation of European Biochemical Societies for a Fellowship awarded to P.R. and the BBSRC for a research grant awarded to R.N.P. The core facilities of the Cambridge Centre for Molecular Recognition are supported by the BRSRC and The Wellcome Trust.

1 Reed, L. J. and Hackert, M. L. (1990) J. Biol. Chem. 265, 8971-8974 
2 Perham, R. N. (1991) Biochemistry 30, 8501-8512

3 Berg, A. and de Kok, A. (1997) Biol. Chem. 378, 617-634

4 Fujiwara, K., Okamura-Ikeda, K. and Motokawa, Y. (1992) J. Biol. Chem. 267, 20011-20016

5 Okamura-Ikeda, K., Ohmura, Y., Fujiwara, K. and Motokawa, Y. (1993) Eur. J. Biochem. 216, 539-548

6 Macherel, D., Bourguignon, J., Forest, E., Faure, M., Cohen-Addad, C. and Douce, R. (1996) Eur. J. Biochem. 236, 27-33

7 Salmons, D., Thornton, C. G., Murtif, V. L., Kumar, G. K., Haase, F. C. and Wood, H. G. (1988) J. Biol. Chem. 263, 6461-6464

8 Knowles, J, R. (1989) Annu. Rev. Biochem. 58, 195-221

9 Holak, T. A., Nilges, M., Prestegard, J. H., Gronenborn, A. and Clore, G. M. (1988) Eur. J. Biochem. 175, 9-15

10 Crump, M. P., Crosby, J., Dempsey, C. F., Parkinson, J. A., Murray, M., Hopwood, D. A. and Simpson, T. J. (1997) Biochemistry 36, 6000-6008

11 Reed, L. J. (1974) Acc. Chem. Res. 7, 40-46

12 Perham, R. N. (1975) Phil. Trans. R. Soc. London Ser. B 272, 123-136

13 Howard, P. K., Shaw, J. and Otsuka, A. J. (1985) Gene 35, 321-331

14 Morris, T. W., Reed, K. E. and Cronan, Jr., J. E. (1995) J. Bacteriol. 177, 1-10

15 Fujiwara, K., Okamura-Ikeda, K. and Motokawa, Y. (1997) J. Biol. Chem. 272, 31974-31978

16 Walsh, C. T., Gehring, A. M., Weinreb, P. H., Quadri, L. E. N. and Flugel, R. S. (1997) Curr. Opin. Chem. Biol. 1, 304-315

17 Wallis, N. G. and Perham, R. N. (1994) J. Mol. Biol. 236, 209-216

18 Reche, P., Li, Y.-L., Fuller, C., Eichhorn, K. and Perham, R. N. (1998) Biochem. J. 329, 589-596

19 Dardel, F., Davis, A. L., Laue, E. D. and Perham, R. N. (1993) J. Mol. Biol. 229, 1037-1048

20 Green, J. D. F., Laue, E. D., Perham, R. N., Ali, S. T. and Guest, J. R. (1995) J. Mol. Biol. 248, 328-343

21 Ricaud, P. M., Howard, M. J., Roberts, E. L., Broadhurst, R. W. and Perham, R. N. (1996) J. Mol. Biol. 264, 179-190

22 Berg, A., Vervoort, J. and de Kok, A. (1996) J. Mol. Biol. 261, 432-442

23 Berg, A., Vervoort, J. and de Kok, A. (1997) Eur. J. Biochem. 244, 352-360

24 Pares, S., Cohen-Addad, C., Sieker, L., Neuburger, M. and Douce, R. (1994) Proc. Natl. Acad. Sci. U.S.A. 91, 4850-4853

25 Brocklehurst, S. M. and Perham, R. N. (1993) Prot. Sci. 2, 626-639
26 Athappilly, F. K. and Hendrickson, W. A. (1995) Structure 3, 1407-1419

27 Yao, X., Wei, D., Sodern, C., Summers, M. F. and Beckett, D. (1997) Biochemistry 36, 15089-15100

27a Kraulis, P. J. (1991) J. Appl. Crystallog. 24, 946-950

28 Gruys, K. J., Datta, A. and Frey, P. A. (1989) Biochemistry 28, 9071-9080

29 Hale, G. and Perham, R. N. (1979) Eur. J. Biochem. 94, 119-126

30 Bleile, D. M., Munk, P., Oliver, R. M. and Reed, L. J. (1979) Proc. Natl. Acad. Sci. U.S.A. 76, 4385-4389

31 Russell, G. C., Williamson, A. and Guest, J. R. (1989) FEMS Microbiol. Lett. 60, 267-272

32 Reed, L. J., Koike, M., Levitch, M. E. and Leach, F. R. (1958) J. Biol. Chem. 232, 143-158

33 Graham, L. D., Packman, L. C. and Perham, R. N. (1989) Biochemistry 28, 1574-1581

34 Waldrop, G. L., Rayment, I. and Holden, H. M. (1994) Biochemistry 33, 10249-10256

35 Wallis, N. G., Allen, M. D., Broadhurst, R. W., Lessard, I. A. D. and Perham, R. N. (1996) J. Mol. Biol. 263, 436-474

36 Graham, L. D. and Perham, R. N. (1990) FEBS Lett. 262, 241-244

37 Morris, 'T. W., Reed, K. E. and Cronan, Jr., J. E. (1994) J. Biol. Chem. 269, 16091-16100

38 Green, D. E., Morris, T. W., Green, J., Cronan, Jr., J. E. and Guest, J. R. (1995) Biochem. J. 309, 853-862

39 Brookfield, D. E., Green, J., Ali, S. T., Machado, R. S. and Guest, J. R. (1991) FEBS Lett. 295, 13-16

40 Yang, Y.-S. and Frey, P. A. (1989) Arch. Biochem. Biophys. 268, 465-474

41 Ali, S. T., Moir, A. J. G., Ashton, P. R., Engel, P. C. and Guest, J. R. (1990) Mol. Microbiol. 4, 943-950

42 Dardel, F., Packman, L. C. and Perham, R. N. (1990) FEBS Lett. 264, 206-210

43 Fujiwara, K., Okamura-Ikeda, K. and Motokawa, Y. (1996) J. Biol. Chem. 271, 12932-12936

44 Wilson, K. P., Shewchuk, L. M., Brennan, R. G., Otsuka, A. J. and Matthews, B. W. (1992) Proc. Natl. Acad. Sci. U.S.A. 89, 9257-9261

45 Cronan, Jr., J. E. (1989) Cell 58, 427-428

46 Reddy, D. V., Shenoy, B. C., Carey, P. R. and Sönnischen, F. D. (1997) Biochemistry 36, 14676-14682

47 Cohen-Addad, C., Pares, S., Sieker, L., Neuberger, M. and Douce, R. (1995) Nature Struct. Biol. 2, 63-68

Received 1 April 1998 